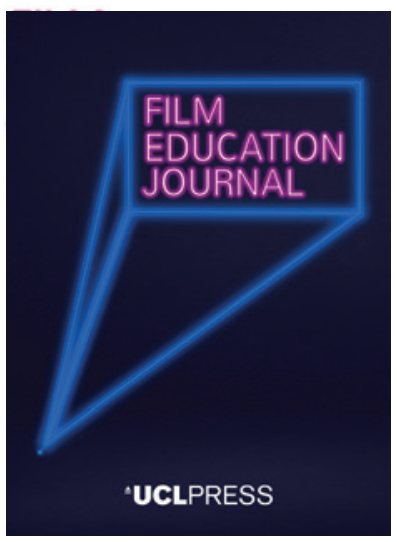

UCLPRESS

FILM EDUCATION JOURNAL

ISSN 2515-7086 (Online)

Journal homepage:

https://www.uclpress.co.uk/pages/film-education-journal

\title{
Securing a place for film within the ongoing life of a Scottish state secondary school
}

Michael Daly, Jacqueline Thomson and Jamie Chambers (i)

\section{How to cite this article}

Daly, M., Thomson, J. and Chambers, J. (2020) 'Securing a place for film within the ongoing life of a Scottish state secondary school'. Film Education Journal, 3 (2), 160-74. Online. https://doi.org/10.14324/FEJ.03.2.04

Submission date: 12 March 2020

Acceptance date: 12 May 2020

Publication date: 26 November 2020

\section{Peer review}

This article has been peer-reviewed through the journal's standard double-blind peer review, where both the reviewers and authors are anonymized during review.

\section{Copyright}

(C) 2020 Daly, Thomson and Chambers. This is an open-access article distributed under the terms of the Creative Commons Attribution Licence (CC BY) 4.0 https://creativecommons.org/ licenses/by/4.0/, which permits unrestricted use, distribution and reproduction in any medium, provided the original authors and source are credited.

\section{Open access}

The Film Education Journal is a peer-reviewed open-access journal. 


\title{
Securing a place for film within the ongoing life of a Scottish state secondary school
}

\author{
Michael Daly - John Paul Academy, Glasgow, UK \\ Jacqueline Thomson - John Paul Academy, Glasgow, UK \\ Jamie Chambers* - University of Edinburgh, UK
}

\begin{abstract}
Scottish teachers interested in working with film frequently find themselves faced with a significant challenge in acquiring the confidence and experience to work with this medium in the classroom. Film education does not yet form any significant part of Scottish teacher training programmes and, as such, incorporating film in a medium-specific manner into curricular teaching can be a challenge. This article explores the perspectives of two secondary school teachers at John Paul Academy in Glasgow, who, with the support of UK-based film education charity Into Film, have begun to explore concrete, long-term ways of integrating film education into the school curriculum.
\end{abstract}

Keywords: Joker, Todd Phillips, English, media studies, Scottish Qualifications Authority (SQA), Scotland, Glasgow

\section{Introduction}

Despite the ubiquitous presence of film in children's lives, film education remains relatively peripheral within primary and secondary schools in Scotland. There is as yet no film-focused qualification for Scottish children to choose at secondary level, and until relatively recently film has found a somewhat uncomfortable fit with the more traditional notions of 'literacy' within Scotland's Curriculum for Excellence (the national guidelines specifying the purposes and focuses for the education of students aged 3-18). There continue to exist a number of film education initiatives run by third-sector organizations and community groups (such as Glasgow's GMAC Film hub, Aberdeen's Station House Media Unit (SHMU) or Screen Education Edinburgh), or by cultural institutions and cinemas (such as Glasgow Film or Edinburgh's Centre for the Moving Image), which attempt to help young people engage with cinema either as viewers or through early practical explorations of filmmaking. These initiatives, however, tend to focus on extra-curricular work taking place outside the school day, or depend heavily upon the involvement on outside practitioners and organizations whose engagement with school life is inevitably circumscribed. In 2020, film is therefore yet to find a more secure, long-term place within the Scottish school curriculum.

Scottish teachers interested in working with film thus frequently find themselves faced with a significant challenge. Film education does not yet form any significant part of university-based teacher training programmes in Scotland and consequently, particularly for those without a specific background in film (whether that be an undergraduate engagement with film studies or some degree of filmmaking experience), incorporating film in a medium-specific manner into curricular teaching 
can be a challenge, requiring aspects of confidence using film theory and film practice it is not always easy to attain. And yet, in our experience, in the small yet growing number of instances in Scotland where film has been integrated more successfully into the ongoing life of a school - moving beyond extra-curricular or time-limited projects to retain an ongoing presence within school life and curriculum - this tends to be done as much on the initiative of teachers on the ground as it is a result of initiatives led by external organizations. Frequently, as detailed later in this article, programmes of film education that are subsequently able to achieve a secure, ongoing place within school life embody a complex partnership between the initial impetus and support provided from an external organization and the more contingent, decisive initiative of classroom teachers. Despite what might thus be considered a relative absence of higher-level, 'top-down' leadership on how film is integrated into Scottish classrooms, various teachers on a localized level - ourselves included - have been exploring the place of film in the classroom, and within particular schools or clusters, managing to find more secure, organic places for film within school life than often seems to be afforded by more short-term projects and extra-curricular engagements.

This tendency is also reflected in the accounts of film education that have appeared to date in the Film Education Journal, which have tended to focus either on 'top-down' or externally motivated initiatives to find places for film in classrooms. This article takes a different approach in exploring - through critical reflection on our own experiences at John Paul Academy, an inner-city secondary state school in Glasgow - how we might, as teachers, seek to find a more secure place for film within school life. In sharing our experiences, we seek both to demystify aspects of the process of finding places for film in both curricular and extra-curricular contexts, while also encouraging and empowering other teachers in Scotland and further afield to follow in our footsteps. In doing so this article focuses primarily on my (Michael Daly's) experience, coming to film from a relatively unspecialized background as an English teacher, in gaining the confidence to lead the process of embedding film within John Paul Academy's broader curriculum. In doing so I draw also on the parallel experiences and input of my colleague Jacqueline Thomson, a fellow English teacher at John Paul who has similarly explored the possibilities of using film in the classroom, and also of film education practitioner (and Film Education Journal editor) Jamie Chambers, who has helped us to place our experiences in context, while providing additional aspects of editorial support.

John Paul Academy is an inner-city secondary state school in Glasgow consisting of roughly a thousand pupils. Glasgow's Centre for Population Health (GCPH) recently presented the troubling statistic that one in three children in Glasgow are living in poverty (GCPH, 2020). Of John Paul Academy's current school roll, 75 per cent of our students are categorized as living in residential areas classified by the Scottish Government as SIMD1 and SIMD2 (Scottish Index of Multiple Deprivation). This in turn means three out of four of our current students live in neighbourhoods considered among the most socially and economically deprived areas in the United Kingdom. In 2015, Scotland's First Minister Nicola Sturgeon launched the Scottish Attainment Challenge, an initiative geared towards addressing fundamental inequities in education, with the aim of closing Scotland's poverty-related attainment gap. Alongside this, Glasgow City Council has been pursuing an authority-wide focus on the improvement of literacy, introduced in 2015 and scheduled to run until 2020. This initiative, entitled Literacy for All (Glasgow City Council, 2015b), serves to 'increase the learning experience for pupils living in the most deprived $20 \%$ of postcodes' (Glasgow City Council, 2015a). As we detail later in this article, it has been our experience that working with film in both 
curricular settings (in mine and Jacqueline's respective English and media classrooms, and further sites throughout the school through Interdisciplinary Learning and Wider Certification programmes) and extra-curricular settings (in our after-school film club) has not only played a pivotal role in John Paul Academy's attempts to address the attainment gap, but has also proven an engaging way of further promoting literacies both film-related and more traditional - within our school.

In our efforts to find a place for film in John Paul Academy, we have benefited considerably from the input and support of UK-based film education charity Into Film, who both provided the initial impetus for our engagement with film and have subsequently supported us in shaping an approach to film education tailored to the specific needs of our school. While this support from an external organization such as Into Film played a pivotal role in supporting us in finding our feet in the use of film in the classroom, it ultimately remains our experience that the interior perspective teachers have on the complex ongoing warp and woof of school life means that we are frequently better placed to concretely institute ongoing approaches to film education in schools that are more deeply rooted and longer lasting. John Paul Academy's engagement with film education is thus best seen as collaborative, whereby the support of an external organization was subsequently consolidated and developed by those of us with a detailed knowledge of the school and its students, who were thus able to translate the use of film from more recreational, extra-curricular contexts into curricular learning environments in the classroom.

The following article presents a critical reflection that maps the different stages of our engagement with film at John Paul Academy, starting in an extra-curricular capacity as part of the school film club, before working with film in a more in-depth manner as part of our Higher English and media teaching, and eventually finding a standalone place for film education in our Wider Certification programme.

\section{First encounters with film}

Having trained initially as English teachers, our first encounter with film arose as much out of pragmatic necessity as from a desire to broaden our horizons. As probationary teachers it was impressed upon us towards the end of training it would be advisable, when we were beginning the process of looking for jobs, for us to have run some form of after-school club, as a means of demonstrating at interview the contribution we would be able to make to wider school life. We were advised to think about how we could demonstrate our experience and contribution simultaneously at the classroom level, departmental level and to the whole school. One of the simplest ways to do the latter was to have had experience running some form of after-school club. We (myself and Jacqueline) therefore seized upon an invitation from UK-based charity Into Film - then called Film Club - who we first encountered at a Glasgow City Council Probationer Meeting for Continuing Professional Development, to draw upon their resources in starting such a club.

With Into Film's support, we began a weekly after-school club on a Wednesday, during which students could watch a film from 3.30 p.m. until 5.00 p.m. in a voluntary, extra-curricular capacity. Initially the screenings took place in one of John Paul's media classrooms, where there was a projector. For a while, as numbers started to grow, we moved to a larger space in the school hall, where we had access to a bigger screen and the ability to black out the room like a cinema. We latterly found, however, that the hall's open-plan architecture meant that other students would frequently walk past and look in, so, in order to maintain a safe, comfortable space for the group's discussions, 
where students could talk without feeling unduly watched, we reverted to the more intimate, comfortable space of the media classroom.

Recalling the Attainment Challenge's imperative for Scottish schools to address inequities of access, a further motivation behind starting an extra-curricular film club was that it would open up access to watching relatively new releases at a moment when - given rising ticket prices - our students were in danger of being priced out of going to the cinema. Screening films in a Scottish school in this manner is not entirely free, as we are required to pay a licensing fee, notifying our senior management team as to the films screened by the club, which then feeds into licensing costs paid quarterly by the school. (While this is a cost required either of schools or local authorities in Scotland, the Department for Education covers such licences for state schools in England.) Here we were lucky to have the early support of our principal and head teacher (who, like us, were won over by Into Film's promotional DVD, which succinctly conveyed the potential benefits of starting a film club) and we found throughout our attempts to find a place for film at John Paul Academy that the support, confidence and trust of senior management remained a crucial factor.

Unsurprisingly, we quickly found running a film club to be both significantly more demanding and more rewarding than simply pressing play on a DVD and leaving our students to watch a film. In our early sessions we began by using relatively new releases that had already found success at the UK box office in the hope of generating interest among our students. One of the biggest challenges in running a school film club we found, however, was - not dissimilar to that of running a cinema - of ensuring our programming was able to hold onto our audience's attention and approval! We found our audience numbers would dwindle the week after we had shown a film that did not find favour with our students, often for surprising reasons. In 2018, shortly after it had screened in cinemas, we showed Ron Howard's Solo on the assumption that, as a new piece of contemporary popular cinema, it would meet with approval with our film club. We were somewhat taken aback then when the film met with disapproval from our student audience, due to the film's poor performance at the US and UK box offices! Students seemed surprisingly sensitive to the general critical and commercial reception of films, voicing further scepticism about our choice of Solo given that the previous Star Wars film too, The Last Jedi (which had received mixed critical reviews after a somewhat unorthodox take on the Star Wars mythology) was 'garbage'. In instances when our programming met with such disapproval, it was clear we needed to find a film with a significant hook in order to win back the trust of our growing audience.

In general, even after the club began to develop a relatively stable audience of students, we still found (and continue to find) many students tended to dip in and out of screenings from week to week. The club tends to consist of a smaller, core group who attend weekly, with the struggle then becoming how we keep the more peripheral, transient students around them engaged as well. In general, we have found our audience tends to be significantly weighted in terms of gender towards female students, with a typical audience consisting of 60-80 per cent female. In our experience, our male students seem to be more affected by the opinions of their peer group. Given the club is a voluntary, extra-curricular activity that often clashes with after-school games of football, it is perhaps not seen by all the boys at John Paul Academy as entirely 'cool'. In general, John Paul Academy is quite a sports-orientated school, priding itself on football, dance and netball activities, and in this respect we suspect film may be viewed by some students as an activity for those less interested in sports. 
Over time, as pupils began to return regularly to film club sessions, and our numbers started to expand, students became increasingly keen to share their views about the films we were watching together. As a result, we began to allocate more time for group discussion, and eventually arrived at a format whereby every film club meeting would begin with a discussion about the film we had watched the previous week. In approaching the discussions with our students we were conscious about trying to create a space in which everyone felt safe and able to share their opinions. We found (and continue to find) it was important to give students time to express themselves: to go around the room and try to hear what everyone wanted to say. Sometimes we would find we ourselves needing to assist students in elaborating upon and unpacking the reasons behind their opinions. Rather than simply saying 'That film was crap', we would ask 'Why do you think it was crap?'; 'What was the crappest bit?'; 'Why was that bit so crap?'; 'Did you not like that shot?' Here, we were frequently struck by how our students' opinions, sometimes written off all too easily as a nonchalant dismissal, were grounded in the visual parameters of the film: 'It was that GoPro shot. It was too shaky.' Discussions of this sort would then allow us to encourage the students to put themselves in the position of the filmmakers, and ask how they themselves might have done things differently: 'So if you were going to make that, what would you do?'

Just as importantly, we wanted to create a space whereby students were encouraged to listen respectfully to each other, and to the opinions of other students that they might not necessarily agree with, and to subsequently engage with others in discussion. At John Paul Academy, the way our students talk to each other in the playground can sometimes seem somewhat confrontational. Film club therefore created the opportunity of opening up a discussion space in which we could encourage students to learn to engage with each other in a more constructive way. We would frequently use the idea of 'two stars and a wish' (two positive comments alongside one that was more critical) when encouraging students to respond to the viewpoint of another. The more comfortable our students became in discussing films, the more we felt able to challenge the group to build up their counterarguments and engage in a lively debate. Frequently we found such debates were not just between the students but equally between the students and us, the teachers and curators! We frequently found that our own idea of 'the classics' was challenged by students coming to the films with new eyes and within a very different generational context. Frequently films we perceived as being highly canonic would receive lukewarm responses. When it was screened to our older students, our audience couldn't comprehend why we, the teachers, felt the shower scene in Hitchcock's Psycho was so traumatic. Similarly, when we watched The Birds, many students fell into fits of laughter during the sequence in which the birds chase the school children. Perhaps the most heated debate surrounded The Empire Strikes Back, which I deliberately presented, provocatively, as 'the greatest film of all time', in the hopes of setting up a lively debate among the group. I was not disappointed, for the students expressed their disgust that for 'the greatest film of all time', I had picked a film where 'the bad guys win'. This led to a heated, albeit productive, debate about the moral dimensions of films in which the narratives do not reach a happy resolution (and the differences between story form and real-world contexts), and to discussion of how our students might themselves change the ending of certain films were they able to reshape their narratives.

One of the resources provided by Into Film for film clubs is both the means and encouragement for students to write their own reviews of films watched in the club. Each participating student is assigned their own Into Film account, and is able to search Into Film's database for a given film before following the site's link to 'write review', 
incentivized through 'review of the week' features and prizes such as DVDs and other film-related memorabilia. We quickly found that it became a natural progression for students to review films that they had already seen, alongside films watched outside the film club.

These reviews provided students with a further opportunity to express themselves honestly, writing without fear of being corrected regardless of their level of written literacy. This led to further contrasting opinions and contested notions of cinematic value between those of us running the club and the students attending. One particular debate arose when I brought another of my favourite films to share with the group. As part of our efforts to encourage continued engagement with the film club we had begun to run certain months linked by theme, one of the most popular among our students being 'Teacher's Choice'. Here colleagues from across the school presented their favourite films to the students, joining us before the screening to discuss why a given film was their favourite. This created an interesting new sense of vulnerability for the participating teachers, and - as we will discuss further - disrupted to an extent the authority of the teacher in regard to the students. Pupils were genuinely surprised when a formidable deputy head teacher joined the group to tell them his favourite film was Lady and the Tramp (Clyde Geronimi, Hamilton Luske, Wilfred Jackson, 1955) because he used to watch it with his daughter during her childhood. When it came to my turn, I chose We Bought a Zoo (Benjamin Mee, 2011) - for me, a heartwarming tale about a man who, after the death of his wife, buys a rundown zoo with his family which I felt the group would appreciate. As it turned out, I was very wrong, as one of our students eloquently summarized in their review:

\section{We Bought a Zoo-0/5}

We bought a boo [sic] is by far the worst film I've ever seen its about a man whose wife died his daughter can't shut her mouth about it and his son is a really bratty emo but what makes this the worst film is that its constantly trying to milk the fact they bought a zoo like oh my god you bought a zoo no one cares $>$ :( (Pupil A, age 12)

While providing a good incentive for students to develop their written literacy (which in turn subsequently allowed us to track the progress of students' written work), such reviews provided an insight into how students were beginning to build confidence in expressing their own thoughts, opinions and tastes as filmgoers in an extra-curricular context in which their work was not marked. Frequently students' writing moved outside the formal parameters of reviews to communicate more urgent, expressive descriptions of their feelings and responses: an expression of what they felt, in written form. In some instances the reviews focused on instinctual feelings as to the film's value, and whether it made a valuable contribution to the broader context of a franchise:

\section{Rogue One: A Star Wars Story - 1/5}

This movie was worse than a stormtroopers aim. the star wars series should have been left where it was it was already very good but this movie in my eyes RUINED the star wars collection. there was so much new concepts in this movie that contradicts the original line of movies. I WOULD NOT WATCH IT AGAIN (Pupil B, age 14)

Sometimes students' more critical opinions reflected a sense they felt the film's narratives were implausible: 


\section{Elf $-1 / 5$}

I personally didn't like the film i thought it was kinda annoying the whole cheery Christmassy thing was really getting on my nerves and the whole idea of him not knowing he was human and an elf was really annoying cause you would think he would know! So after seeing many times i say it was one of the most terrible Christmas films i've watched! (Pupil C, age 13)

Elsewhere, as perhaps tended to be more the case with older students, critical opinions were sometimes based on the moral dimensions of a film:

\section{Hacksaw Ridge - 2/5}

Should take tips from Hitchcock. Overall, the film was pretty bad.

A good thing is that Andrew is a pretty boy who is also a sneaky boy. The bad things are that you shouldn't get a British actor to do an American accent and stop jumping from serious moments that show people who are traumatised from war to glamorous scenes of an attractive actor showering ... (Pupil D, age 17)

As with the reference to Hitchcock, many students evaluated films by placing them in a wider context of references, and frequently found value in the manner in which certain films referenced other narratives:

\section{The Lion King - 5/5}

I love that the lion king is inspired by Shakespeare's Hamlet. It was very surprising but I can see how. The movie is great and the songs are good to listen to. (Pupil E, age 14)

\section{Ready Player One - 2/5}

My teacher lied. I believe it was the great Albert Einstein that said 'Nothing is impossible when you put your mind to it' except making Ready player one good.

The take backs and 90s reference is the movie is good but that's the only thing. The book is better than than [sic] the movie a number of reasons I cannot put into words. It would be a beater trilogy than a movie. Dose not come recommended. (Pupil F, age 12)

Reflecting upon our experiences working with film in the extra-curricular setting of a film club, perhaps one of the most valuable aspects has been the manner in which film clubs allow students, within a school setting, to be able to develop their own opinions, which - not being marked - were thus neither 'correct' or 'incorrect'. As we would encounter again, film seemed to create a space within a school context in which students felt some freedom from an imposing teacherly authority. Our film club arguably opened up more of a horizontal space within the school in which teachers were less authoritative (and, at times, more vulnerable) and wherein there was at least the opportunity for students to develop a sense of their own agency, in a manner more exempt from the judgement and assessment of the school.

While the film club took place on an extra-curricular basis, we found that it served (alongside the opportunities to encourage written and verbal literacy work around the films) as a powerful gateway - both for our students, and for ourselves as teachers - to subsequent engagements with film in more curricular settings. Perhaps 
most crucially, the film club allowed Jacqueline and myself as teachers to build our confidence working with film within a school context, in a manner that we were then able to translate into classroom settings as we discuss later in this article.

\section{Integrating film as an optional 'text' in SQA English exams: Joker and Skyfall}

As English teachers, incorporating film into our teaching had, up until our encounter with Into Film, been somewhat frowned upon during our training. Within the context of English teaching it frequently seemed to us film was seen as a soft or lazy option one might use with students of lower ability, or with those with whom it was more difficult to engage. Looking back on these attitudes now, it's easy to see the disservice such perspectives do not only to students, but also to film as a subject worthy of study in its own right. To position film in such a manner is to overlook its considerable complexities and sophistication as a medium, while simultaneously overlooking young people's capacity to understand and respond to it. In hindsight, the notion of film as an 'easy option' is arguably itself a somewhat confused misconception, positioning film's relevance and power for young people conservatively, as indicative of its lowered educational value as a medium. Conversely, we argue film's apparent ability to engage young people more readily than other literary or media forms should be seen as a source of power in classroom settings rather than an easy option to fall back on when more traditional modes of study prove less successful. Alongside novels and poetry, film seems somewhat unique in the relative immediateness in which it is able to communicate to young people. While one is unlikely to glean much from looking at a book before one is able to read, most of us can watch a film and - without much specialist knowledge of film theory or film practice - still be able to experience the film, develop an opinion and subsequently contribute to a discussion about it. As other writers in the Film Education Journal have explored (Bazalgette, 2018), children start to learn the language of film from as early as 18 months - a much younger age than reading - and continue their engagement, viewing and reviewing films and other screen-based media, before they get to school. Further, while it can take (at best) a week to read a book, it only takes two hours to watch a film, removing further barriers to ensuring full class engagement. While such arguments may seem to risk reinforcing conservative conceptions of the 'easiness' of film, we argue film possesses just as much complexity and sophistication as the novel, a complexity and sophistication that, however, many young people today seem significantly better positioned to access.

In our experience film is a medium that has an energy and relevance for young people that other literary and media forms - such as novels - do not. As English teachers, we are increasingly finding, whether we wish to admit it or not, that the texts we would ideally wish children to engage with are changing. The book - at least in its traditional form - is becoming almost obsolete outside the classroom. Contrastingly, film is readily and abundantly present within students' lives. This subsequently has implications for how students are able to link and extend the engagements they make with texts in the classroom with the broader cultural contexts of their lives. While it has been rare in our experience that students seek out further books by F. Scott Fitzgerald after reading The Great Gatsby, they frequently recounted to us watching other films directed by Todd Phillips, or starring Joaquin Phoenix, after studying Joker (2019). As part of the recent Reading Challenge (launched alongside the Scottish Government's initiative on closing the attainment gap), Sue Ellis argued that 'for pupils who often read for pleasure, attainment rises and the attainment gap associated with poverty 
narrows' (Scottish Book Trust, 2019). We would make a similar argument in advocating for the use of film in classroom settings: if attainment is linked not only to engagement but also to enjoyment, this provides a compelling case for the educational value of film in school life. From our experiences working with film at John Paul Academy we have come to see film again as allowing a potential levelling of the playing field, where - as with our film club - the differences between levels of literacy among students are less manifest and obstructive, and the authority of the teacher is not as unassailable as when contending with a piece of classic literature.

These points were aptly illustrated when we began to start using film more regularly as part of our English teaching, particularly for students studying for their Scottish Qualifications Authority (SQA) Higher exams (the exams typically taken by 16-17-year-old students in their fifth year of secondary school). When sitting Higher English, Scottish students are given the option to choose a 'text' that they are then asked to write an essay on in the exam, in response to a relatively general, open-ended essay question. While it is still relatively rare in practice, students can - alongside novels, poems and plays - now take a film into the exam as one of their chosen 'texts'. Here, while film education takes place within the context of English literature studies, films are taught (as is at least the case at John Paul Academy) with as much attention to medium-specific parameters such as camera angle, colour, production design and editing, as those narrative elements most resembling a novel (plot, character and so forth).

When we were training to be English teachers there was something of a running joke regarding the recurrence of The Godfather (Coppola, 1972) and The Shawshank Redemption (Darabont, 1994) as seemingly the only films that would appear in the context of English teaching. (Here, the most recent examination report from the SQA (SQA, 2019) seems to signal that film remains relatively low on the list of texts written about by candidates, and The Godfather retains its pride of place!) There is a further irony that, as one does not need a specific qualification in order to teach media in a school (and as there is currently no media-specific option in Scottish graduate teacher training), the majority of media studies teachers in Scotland tend (in our experience at least) to be those who trained initially as English teachers. During my own time training to be an English teacher seven years ago, we received only one afternoon session on media, which focused as much on the information displayed on the back of food packaging as it did on film (Bazalgette, 1992). My experience subsequently working with film in curricular settings has reflected the sense that film as a medium in Scottish classrooms falls somewhere between English - in which it can be treated as a text (albeit often with an emphasis on the narrative parameters most resembling a novel) - and media, where there is less of a textual focus and individual 'texts' are presented more for the manner in which they exemplify media and broader societal factors. Despite these complexities, we are finding that there is a growing number of engaged Scottish teachers working across both media and English teaching who are increasingly responding to the paucity of training and resources by creating and sharing materials of their own, supporting each other to teach different films with their classes. At this point, it is known among our network of teachers that I teach and am able to share the resources to teach Skyfall (Mendes, 2012) and Ready Player One (Spielberg, 2018), whereas we are aware of teachers elsewhere in Scotland who have developed and shared great resources for films such as Black Panther (Coogler, 2018) and Get Out (Peele, 2017).

Returning to my experiences of teaching film in Higher English classrooms, during the year students spend studying for their Higher they are taught a series of 
texts from which they select on average two (a first choice and a back-up) to take into the exam. Frequently I will adjust the series of texts I teach to fit the class I am working with, trying to find books or films with which students seem able to strongly engage. While I encourage students to make suggestions, I also need to ensure a film's content allows sufficient scope for exploration, whether that be the historical context in a film like Dunkirk (Nolan, 2017), or the rich popular culture references in a film like Ready Player One. During the past school year I encountered significantly different responses from my Higher class when teaching first a novel - William Golding's Lord of the Flies - and then a film - Todd Phillips's Joker. I was teaching a class of sixthyear students (17-18 year olds) resitting their Higher English after having failed it the previous year. Working with the class, I had the distinct sense many of the students were disillusioned and ready to leave, having reached a sense of their expiry date with education. Finding my students were having difficulties engaging with Lord of the Flies, I gave them the choice in January either to move on to a short story or to study Joker. They overwhelming voted for the latter and, given the relatively recent release of the film, I had little time to develop materials, having to thus adopt a more responsive approach where I adapted my teaching lesson to lesson. Despite this, however, where I had found it challenging to communicate my enthusiasm for Lord of the Flies, I found that my own interest in and enthusiasm for Joker met with a similar level of interest and enthusiasm among the students.

Early on in our sessions on Joker I taught several lessons specifically focusing on film language. I looked at camera shots with the class, with which the students familiarized themselves before experimenting with putting the same shots into practice with their camera phones. In my experience, students glean only a limited amount from sketching storyboards in their jotter and the best way to learn about camera shots is thus to try them out for themselves. After trying out different shots on their phones, I then asked students to make a short film, around 60 seconds long, using only four camera shots. While this sort of activity is not typical in English classrooms, it proved useful in helping students ground theoretical concepts in their own experience, leading subsequently to a strong basis for discussion about the intentions behind certain shots.

Following on from practical work, I would then ask students questions about why they had chosen a particular angle and not another: what impact did the angle they chose have on the character in the shot? This then allowed for a rich discussion on intentionality in filmmaking, in starting to help students unpick the pattern of decisions made by a director. Alongside this, we watched videos of Phillips himself breaking down his directorial decisions in detail during the opening sequence of Joker (Vanity Fair, 2019). We would watch particular sequences in the film (such as the opening) five or six times, each time taking a different focus. While the first time we would focus on experiencing the film as a whole, in latter passes I would direct the students' focus to particular cinematic parameters. In a second pass we would slow things down and watch the sequence shot for shot, building a timeline and discussing the impact of the different shots. On a subsequent pass we would then discuss colour and the connotations of different colour palettes. The question of 'tone' is perhaps a bit more advanced than I would usually have attempted with a class of this sort, but because of the level of engagement with Joker I found we were able to explore some quite abstract territory. Latterly my students began to joke with me that following our classes together they were no longer able to simply sit back and enjoy a film. 'You've ruined film!', I would be told, 'I can't go to the pictures with my girlfriend, without thinking all this stuff.' 
Overall, I noticed a significantly greater level of engagement with Joker than I had done with Lord of the Flies. Many of the students told me they were planning to write about Joker in the exam, because they had found it significantly more engaging. Interestingly, the small number of students who seemed less engaged with Joker were those I would perhaps have considered as engaging more easily with the traditional, academic aspects of English teaching. While these students participated willingly enough with our work on Joker, they themselves seemed to have a sense Lord of the Flies was the more conventional pick, and thus a safer option to take into the exam. Elsewhere in the class, however, I found that students who had really struggled to engage and pass early essay attempts with Lord of the Flies were able to engage with Joker at a significantly deeper level.

One particular student, who had only scraped a pass in an essay on Lord of the Flies, was able to produce a much more individuated analysis of Joker. Consider the following excerpts from their essays on, first, Lord of the Flies:

The theme of savagery versus civilisation is first introduced to us through the symbol of the conch shell which makes us think of Ralph as he is the person who first uses it and becomes the leader of the boys. This symbolises authority amongst the boys. At the first assembly Ralph says 'I'll give the conch to the next person to speak, he won't be interrupted.' This suggests civilisation as Ralph is allowing each boy to have an equal say and opinion. If they have the conch, no matter who they are or what age they are they will be given the chance to speak and will be listened to by the rest of the boys. The boys have created the island to be a democratic place which shows a civilised side to them. Contrasting with the symbol of the conch is the symbol of the beast which comes to be associated with Jack as by the end of the novel he is the equivalent of the devil worshipping it.

And, second, Joker:

In the opening sequence of this Oscar winning film, the character of Arthur Fleck is shown to the audience. Lowkey lighting is used to reflect how Arthur is feeling in this moment - it is light on the outside, which is the persona that Arthur gives off, and dark and depressed on the inside, which is how he really feels. The director uses an extreme closeup of Arthur putting his clown makeup on and feeling vulnerable as his eyes are tearful, his lips start to tremble and he does not know how to smile as the audience can see him manipulating his face and forcing himself to smile from him already frowning. This portrays Arthur's life as it is like both a comedy and a tragedy. The audience can see that he is in pain as he is pulling his face in such a manner that he is hurting himself - which is a hint at self-harm. The diegetic sound of the news makes the audience aware of what is going on in and around Gotham City. Gotham City is pushing everyone down, including Arthur due to a financial slump and the social degradation. Later in the film, there is use of an establishing shot of Gotham, showing Arthur as a small figure amidst the huge city and this city is dominating the people living there. This shot shows the recession going on currently and all the shops that are closing down and going out of business.

While I had a sense in the student's writing on Lord of the Flies that they were simply repeating statements and ideas they had heard me use in class, I found there was 
significantly more evidence of autonomous thought and engagement in their writing on Joker, demonstrating greater sensitivity to light, camera performance, tone, sound and symbolism as opposed to their more straightforward thematic analysis of Lord of the Flies. Set alongside each other, these two examples of the same student's work recall Robert Scholes's (1985: 24) discussion of the different levels of textual analysis: the first extract embodies a sense of 'reading' or text within text, whereas the second exemplifies 'interpretation' or text upon text; while with Lord of the Flies the student seems obediently to be following requirements, in their response to Joker they seem to be inhabiting the text themselves, and articulating their own aesthetic response. Interestingly, I frequently had the sense film as a medium allowed more space for students' own subjectivities and interpretations. One student asked me 'You could really write anything, as long as it was in the film?' and among the class there was a sense that film, as a younger medium, had not yet developed the same weight of pre-existing responses and interpretations as a novel the examiners were likely to know as well as Lord of the Flies. Here then, rather than simply memorizing and then reproducing adult opinions that felt distant and remote, students seemed to sense they had more space in which to participate on their own terms.

This sense of greater space for manoeuvre and dynamic approaches could in my experience - be said to benefit teachers as well as students. Generally speaking, there frequently seems a danger within the British school system of an overly telescoped approach to results and exams, whereby teaching becomes less focused on students' own experiences and responses and more upon memorizing and replicating the opinions of their teacher under timed conditions in an exam. This pressure on measurable outcomes manifests both on teachers and students, and I have found myself that teaching can risk becoming regimented and formulaic in the pursuit of good results, an approach that film offers the possibility to disrupt. When I first started to teach the film Skyfall with one of my second-year classes (13-14 year olds), we had just been working on a novel where my approach with the class had been fairly regimented. Here, I had provided the class with ready-made essay plans, to give them an indication of the sort of essays that would achieve good results. I found myself not looking for any degree of interpretive flair or individuality, but rather for students simply to follow the structures I had set out. When it came to Skyfall, a film I had not taught before, I decided to leave things looser, in response to the more enthusiastic, engaged response I was receiving from the class. As a result, I made the decision not to give out template essay plans as I had done in the past, but rather a series of still images drawn from the film to serve as prompts for the students to respond to. Again, the difference in response in terms of the student essays was striking, both in the level of understanding and in the level of analysis. I found again that film afforded a means of reaching some of our most disengaged, unconfident students, who were willing to be much more forthcoming in their responses to Skyfall than they had been to the Darren Shan books I had been teaching previously. As with my experiences in the film club, I frequently found that I often needed to intervene, however, in order to help students unpack what were often sophisticated, subtle responses to the films. One particular student who had had difficulties in the past articulating his thoughts in essay form described to me in conversation how he felt that James Bond's character in Skyfall underwent a three-act transformation. When I encouraged him to elaborate, the student went on to describe how 'at the start he's too old, and there's that thing with the shaving. When he's injured he's not the same. He doesnae look like James Bond.' Following further prompts, the student asked me 'Well, what's that bevvy he always has? Aye. Vodka martini. After he gets shot, he's drinking a beer. James Bond doesnae 
drink beer, so he's not the same.' The student told me 'Well, he's also not wearing his suit. He normally wears a suit', which then allowed us to talk about production design and costume. After describing the film to the point where Bond 'batters the guy on the train', the student then turned the questions on me, asking 'So, what is the first thing he does after that? He shaves. And what does he put on? A tuxedo. So he's back to being James Bond.' From here, I was then able to encourage the student to put the conversation we had just had about the film down onto paper, something of a breakthrough moment for him in getting a greater hold on the form of an essay and in demonstrating to himself he was already capable of a relatively high level of analysis that he simply now needed to get down onto the page.

\section{Conclusion}

Considering the way in which film has previously been viewed as an 'easy' or 'lazy' option in school contexts - more as a form of entertainment than a medium warranting educational engagement - it would seem that in Scottish schools (and teacher training programmes) film has struggled with a similar legitimacy crisis to that it has previously experienced in higher education settings more generally. Since we first began teaching at John Paul Academy, however, the definitions of literacy within Scotland's Curriculum for Excellence have relaxed in order to begin incorporating forms of literacy beyond reading, writing, listening and talking, alongside wider definitions of what can be considered 'a text'. Together with our experiences working with film first in the extracurricular setting of the film club, and subsequently in English and media classrooms, such developments have served to deepen our confidence in working with film as a means of energizing student engagement with a wide variety of activities in school life. Alongside using themed films to bind together our Interdisciplinary Learning Course (a year-long programme for our first-year students (12-13 year olds) taking place throughout the school year in a series of six-week sections, providing opportunities for different subjects to find points of intersection in establishing meaningful, crosscurricular links in students' learning), we have also begun to experiment using film as a means of structuring an alternative curriculum for some of our most vulnerable students, whereby a film such as The Martian (Ridley Scott, 2015) serves as means of animating, cohering and thematizing a diverse set of learning tasks. Most significantly, we have recently begun to offer timetabled film sessions as part of our Wider Certification programme, whereby fifth- and sixth-year students (respectively, 16-17 year olds and 17-18 year olds) are given the opportunity, alongside other aspects of vocationally focused training (such as hairdressing or car mechanics), to spend a double period of 100 minutes each week focusing entirely on film education. Arising initially from an awareness that core members of our film club cohort were now coming into the fifth year and were looking for means to explore their interest in film further in curricular settings, our Wider Certification film option has offered both students and teachers at John Paul Academy the chance to explore both theoretical and practical activities in film education within a curricular setting as part of the core school week.

In our experience at John Paul Academy, we found that film can provide a powerful means through which to begin addressing the attainment gap and engaging with hard-to-reach students in Scottish schools. As a medium already ubiquitously present and valued in students' lives, which can be experienced in relatively short amounts of time and which draws on aspects of literacy young people already possess, film offers the potential to create more equitable points of departure for diverse cohorts of students. Further, given the strength of engagement students tend to have 
with film, it can be a significant means of empowering students in school settings, and even in decentring the authority of teachers in establishing aspects of student agency and autonomy. Equally, working with film can allow teachers an opportunity to adopt approaches to classroom pedagogy that are more responsive and alive to students' cultural experiences outside the classroom. As American educator and author Adam Welcome has written on Twitter 'we can't teach Wi-Fi kids with landline strategies'.

Reflecting back upon our experience of embedding film at John Paul Academy both as a means of energizing and illuminating students' engagement and as an object worthy of study in its own right - our experience with external organizations such as Into Film has been crucial in giving us the initial confidence to begin working with film in both curricular and extra-curricular contexts. In our experience, the support of an organization such as Into Film is invaluable given the current lack of engagement with film during Scottish teacher training, and subsequently in helping teachers without specialist backgrounds to begin advocating for the use of film in diverse aspects of school life.

In conclusion, however, it has also been our experience that, alongside the welcome support of third-sector and cultural organizations encouraging the use of film in Scottish schools, it is ultimately teachers themselves who are best placed to be able to find secure, curricular places for film in the ongoing life of the school. At John Paul Academy, while external support from Into Film provided crucial support and confidence in introducing film within the school on an extra-curricular level, it was upon the initiative of teachers that this engagement was translated into curricular contexts during the school day. Rather than waiting for top-down educational policy interventions, Scottish teachers - supported by valuable organizations such as Into Film - are already finding meaningful and organic ways in which to embed film as an ongoing presence in student school experience, both in and outside the classroom.

\section{Notes on the contributors}

Michael Daly teaches English and media at John Paul Academy. He is an ambassador for Into Film. His film club won Film Club of the Year at the Into Film Awards in 2017. He has collaborated with GMAC, Glasgow Film and BFI. Our Maryhill, an archive film and intergenerational project that Michael's pupils worked on, has been nominated for the 2020 Federation of Commercial Audiovisual Libraries (FOCAL) International Awards. He has presented at the Scottish Learning Festival and Scottish International Film Education Conference.

Jacqueline Thomson teaches English and media at John Paul Academy where she has worked since completing her PGDE at the University of Glasgow in 2013. She is a proud ambassador for Into Film Scotland and works closely with external agencies such as Harvard's Ground Zero, Glasgow Youth Film Festival (GYFF), Film Education Journal and Scottish Youth Film Festival (SYFF). Together with her colleague Michael Daly, she is passionate about the promotion of careers within the creative industries and film-based vocational studies, and has led successful film clubs with pupils from S1 to S6.

Jamie Chambers is a lecturer in film and television at Edinburgh College of Art. He is the founding editor of the Film Education Journal and has worked as a film education practitioner with Understanding Cinema and Cinéma Cent Ans De Jeunesse since 2013. $\mathrm{He}$ is the curator of the Folk Film Gathering (the world's first folk film festival 
(www.folkfilmgathering.com)) and is the director of the award-winning, BAFTAnominated films When the Song Dies (2012) and Blackbird (2013).

\section{Filmography}

The Birds (US 1963, Alfred Hitchcock)

Black Panther (US 2018, Ryan Coogler)

Dunkirk (NL/FR/UK/US 2017, Christopher Nolan)

Elf(US 2003, Jon Favreau)

The Empire Strikes Back (US 1980, Irvin Kershner)

Get Out (US 2017, Jordan Peele)

The Godfather (US 1972, Francis Ford Coppola)

Hacksaw Ridge (US/AUS 2016, Mel Gibson)

Joker (US 2019, Todd Phillips)

Lady and the Tramp (US 1955, Clyde Geronimi, Hamilton Luske, Wilfred Jackson)

The Lion King (US 1994, Jon Favreau)

The Martian (UK/US 2015, Ridley Scott)

Psycho (US 1960, Alfred Hitchcock)

Ready Player One (US 2018, Steven Spielberg)

Rogue One: A Star Wars Story (US 2016, Gareth Edwards)

The Shawshank Redemption (US 1994, Frank Darabont)

Skyfall (US/UK 2012, Sam Mendes)

Solo: A Star Wars Story (US 2018, Ron Howard)

Star Wars: The Last Jedi (US 2017, Rian Johnson)

We Bought a Zoo (US 2011, Benjamin Mee)

\section{References}

Bazalgette, C. (1992) 'Key aspects of media education'. In Alvarado, M. and Boyd-Barrett, O. (eds) Media Education: An introduction. London: BFI/Open University, 199-219.

Bazalgette, C. (2018) 'Researching prior learning: How toddlers study movies'. Film Education Journal, 1 (1), 101-12, Online. http://doi.org/10.18546/FEJ.01.1.09.

GCPH (Glasgow Centre for Population Health) (2020) 'Family and child poverty'. Online. www.gcph. co.uk/children_and_families/family_and_child_poverty (accessed 8 July 2020).

Glasgow City Council (2015a) 'Education, skills and early years: Report by executive director of education'. Online. www.glasgow.gov.uk/CHttpHandler.ashx?id=46963\&p=0 (accessed 8 July 2020).

Glasgow City Council (2015b) 'Glasgow's improvement challenge'. Online. www.glasgow.gov.uk/ article/23800/Glasgows-Improvement-Challenge (accessed 8 July 2020).

Scholes, R. (1985) Literary Theory and the Teaching of Text. New Haven, CT: Yale University Press.

Scottish Book Trust (2019) 'Here's what you can achieve with the First Minister's Reading Challenge'. Online. www.readingchallenge.scot/sites/default/files/2019-01/What_Your_School_Can_Achieve. pdf (accessed 8 July 2020).

SQA (Scottish Qualifications Authority) (2019) 'Course report 2019'. Online. www.sqa.org.uk/files_ ccc/2019HCourseReportEnglish.pdf (accessed 6 October 2020).

Vanity Fair (2019) 'Joker director breaks down the opening scene'. Online. www.youtube.com/ watch? $v=$ awo QuVq2yYc (accessed 8 July 2020). 